$$
\begin{array}{r}
\text { https://doi.org/10.52696/ILMW5019 } \\
\text { Reprints and permission: } \\
\text { The Malaysian English Language Teaching Association } \\
\text { Corresponding Author: } \\
\text { Setiono Sugiharto setiono.sugiharto@atmajaya.ac.id }
\end{array}
$$

\title{
Teacher Agency as Technologies of the Self and as Actionality: Implications for ELT Micro-Centric Policy Making
}

\author{
Setiono Sugiharto \\ Faculty of Education and Languages, \\ Doctoral Program in Applied English Linguistics \\ Atma Jaya Catholic University of Indonesia, Jakarta
}

\begin{abstract}
This article critically examines the notion of teacher agency in light of two important conceptual frameworks: technologies of the self and transitionalist-actionistic, or conduct pragmatism. Using the former framework, teacher agency was analyzed in terms of its inherent status and dynamic flux within one's self, while using the latter it was scrutinized for its transitional-actionistic nature triggered by one's action or conduct. The article then argues that viewing teacher agency from these two vantage points can contribute to our understanding of the crucial role a teacher can play in creating a micro-centric policy of teaching and learning English in a specific locality, as well as of the enactment of this policy by individual teachers in a classroom setting. Implications for this critical examination of teacher agency include the import of the (re)activation of teacher agency, and its enactment both in the policy-making processes and in the teaching practices.
\end{abstract}

KEYWORDS: teacher agency, technologies of the self, transitionalist-actionistic or conduct pragmatism, micro-centric policy of teaching and learning English

\section{Introduction}

In the context of teacher professional development, the notion of teacher agency constitutes a vital element, as it has been argued that teacher agency plays an instrumental role in maintaining institutionalized instructional practice (Bridwell-Mitchell, 2015), in enhancing professional development and school reform (Imants \& der Wal, 2020), as well as in bridging theory and practice (Heikkilä, Iiskala, \& Mikkilä-Erdmann, 2020). Ineluctably, a plethora of studies on teacher agency has cast important light into how agency is conceptualized, perceived and constructed, and how it contributes to the overall quality of education. Nonetheless, the discussions about agency in general, and teacher agency in particular, have yet to explicate more on how individual teachers constantly shape and reshape their potential self within the dominion and 
pressure of educational policies that are often designed in a top-down fashion. Drawing on Foucault's (1988) conceptual framework of “technologies of the self”, as well as on Koopman's (2014) idea of "transitionalist-actionistic, or conduct pragmatism", the article will elucidate the notion of teacher agency from these two vantage points. In light of the former, agency is seen as a construct inherent in one's self in that it cannot only be constructed and reconstructed, but can also be self-fashioned by virtue of one's interest. In this sense, agency is a dynamic entity which changes over time. As for the latter, agency is viewed as residing neither in one's cognitive capacity, nor in one's experiences, but rather in one's conducts or acts. So construed, agency is not constitutive, but performative. The article has three objectives:

- First, it reviews and examines previous studies on teacher agency in the context of teachers' professional development in general, and of English language pedagogy in particular, and suggests that an alternative perspective of viewing the notion of agency be needed.

- Second, it proceeds to the discussion of this alternative perspective drawn upon the theoretical perspectives proposed above.

- Third, it discusses the implications of the alternative perspective of teacher agency for the English language teaching (henceforth ELT) policy making.

In relation to these objectives, the following questions are worth putting forward:

- How do individual teachers interrogate educational ELT policies - which are often onesidedly imposed on them - in their specific local sites?

- How can they articulate their voices in negotiating these policies and create their own micro-centric policy?

- How may they deal with the possible physical, ideological and cultural challenges which may not necessarily accord with their own interests?

In so doing, the article is expected to spark new insights into how teacher agency should be construed and enacted in the context of teaching English in a specific locality.

\section{Teacher Agency: Insights from Previous Studies and Theorization}

Interests in theorizing and studying teacher agency have been motivated primarily by the multifaceted aspects of the notion of agency itself. Indeed, a burgeoning study on the issue has testified the robustness of the term. Samoukovic (2015), for example, views teacher agency from the perspective of critical pedagogies, focusing specifically on the power relations both in societies at large and institutional contexts like schools. From her research, she argues that teacher agency needs to be expanded by establishing connections with the societies, so as to become a collective agency. While, as Samoukovic (2015) further asserts, that individual agency has its own merits and potentials "to broaden a teacher's sphere of influence", but it can also "strip a teacher of a protective shield of the system-in-place - if the aim of an action collides with the system-in-place's established procedures" (p. 161). It is therefore collective agency that is seen as having "transformative practices" in balancing this quandary.

Another study on agency was revealingly carried out by Bridwell-Mitchell (2015), who views agency from the sociological point of view. Attempting to advance a theory of teacher agency, 
Bridwell-Mitchell wanted to discover how teacher agency can both change and maintain institutionalized instructional practices in schools. Findings from the study yielded three mechanisms which drive a particular form of teacher agency: (1) peer learning, (2) patterned social interactions, and (3) shared understandings, aims, and practices. Each of these mechanisms, as Bridwell-Mitchell went on to aver, is "moderated or regulated by a set of counterbalancing forces" (p.148); for example, (1a-b) innovation versus socialization in peer learning, (2a-b) diversity versus cohesion in social interactions, and $(3 \mathrm{a}-\mathrm{b})$ cognitive and normative divergence versus convergence in shared understandings, aims, and practices. With this counterbalancing forces, Bridwell-Mitchell concluded that "the balance among these forces determines whether the dynamics of each mechanism support institutional persistence or change" (p. 148).

Rostami and Yousefi (2020) have investigated how agency is exercised among the novice English teachers in Iran using the complexity dynamic/system perspective. This study has revealed that teachers practiced agency by employing dialogic feedback, positioning, and critical incidents. Similar to Samoukovic's (2015) argument, agency is conceptualized through the interdependent of agents in the learning environment, and its emergence is a result of complex negotiation between teachers' identity and environment. In essence, this study stresses the importance of collaboration and interaction between teachers and their environment for practicing and enacting agency. Obviously, the interlocking connection between one's identity and environment in the study aims to achieve collective agency.

No less illuminating study was conducted by Heikkilä, et al., (2020), who have investigated teacher agency from a teacher education lens. They have argued that the notion of teacher agency, or precisely what they call "professional agency," can be best understood from the idea of ownership and authority over learning in a specific sociocultural context. This is of paramount importance, as they contend, especially if there is a divide between theory and practice in the field of teacher education. It is important to note that to a large extent what is theorized by researchers is not necessarily compatible with what is practiced by teachers in classroom. From their studies, Heikkilä et al. have found that agency as voiced by their student teacher participant was always in dynamic flux, unstable, and changing, all of which indicate the dynamics of the nature of agency. Due to this dynamic, they urged the importance of integration between theory and practice.

Conceptualizing agency from the vantage point of ecology, Biesta, Priestley, and Robinson (2020) have argued that agency does not reside in an individual person, but "as an emergent phenomenon of actor-situation transaction" (p. 626). As they have pointed out:

Agency, in other words, is not something that people can have - as a property, capacity or competence - but is something that people do. More specifically, agency denotes a quality of the engagement of actors with temporal-relational contexts-for-action, not a quality of the actors themselves (p. 626).

Their study focusing on the role of belief in teacher agency buttresses this argument. Despite the fact that there are contradictory findings in teacher belief about agency, this does not diminish the values of agency teachers hold in their practices. The point is rather "the promotion of teacher 
agency does not just rely on the beliefs that individual teachers bring to their practice, but also requires collective development and consideration" (Biesta, et.al., 2020, p. 624).

Needless to say, all of the studies on and theorizations of teacher agency reviewed above, irrespective of their foci, have provided us with valuable insights, in that the notion of agency in general and teacher agency in particular are by no means monolithic entities. It is dynamic and changing over time. It is context-bound and socially-embedded. It is thus a multifaceted notion which is subject to multiple interpretations, and hence manifestations, depending upon which perspectives or vantage points one holds. Most importantly, the studies reviewed above have attempted to demonstrate that the enactment of teacher agency in a specific context of practices is crucial for the enhancement of teachers' professional development and pedagogy. For instance, Heikkilä's et al. (2020) idea of professional agency, which views a teacher as an authoritative figure in managing the instructional contexts situated in their sociocultural teaching and learning sites, Rostami and Yousefi's (2020) notion of dialogic feedback, and Samoukovic's (2015) term of collective agency all aim to boost teachers' professional development and pedagogical competence, as these notions imply efforts on the part of teachers to create a space for their professional agentive capacity. With the authority they own and the engagement (through dialogic feedback) with educational stakeholders, teachers will eventually become independent and autonomous in determining their instructional plans and goals, and are able to negotiate institutional and structural policies that may be out of sync with their specific learning sites. It is only through such a continuous process of engagement with the structural and institutional challenges can English language teachers develop their professional and pedagogical skills or competences to the fullest.

Yet what these studies have in common is that they overemphasize the dynamism of agency by virtue of its embeddedness with social conditions or social relations into which agency is shaped and reshaped. Though such a vitality of agency is difficult to refute (and it is not my intention to do so here), we should not lose sights of the fact that agency is still an important property residing in individual person, and that within individuals it is already a dynamic notion per se. Obsession in framing its vitality in terms of its social embeddedness can, in my view, summarily dismiss the idea of agency as a vibrant individual property. For Bandura (2006), agency is inseparable with one's self, for it is the capacity of individuals to initiate intentional acts.

Biesta, et.al., (2020) have previously reminded us of the dynamic of agency, arguing that it is what people $d o$, not what people have (as property, capacity or competence). This is a plausible argument, insofar as it encompasses a dynamic (do), rather than a stative (have) verb. However, the case they are making with the "do" is the doing in relation to the social relation, which is... a quality of the engagement of actors with temporal-relational contexts-for-action... (p. 626). What they seem to overlook is the doing within individuals, a quality and capacity inherent within one's self. It is the unearthing of this quality that seems to have had insufficient attention in the discussion of teacher agency. 


\section{Re-conceptualizing Teacher Agency}

In this section, I will first argue that the notion of agency needs to be re-conceptualized in light of how one can exercise freedom in the enactment of agency. Foucault's idea of technologies of the self is employed here as a framework of thinking. These technologies are "no longer connected to particular forms of knowledge or institutions, but which have validity in all societies, whatever they are" (Nilson, 1998, p. 97). Understanding this idea is of paramount importance before we can embark on the concept of agency as conduct or actionality within an individual.

Agency as Technologies of the Self

A most crucial factor in discussing teacher agency is, in my view, strongly related to the amount of freedom a teacher can exercise to manifest his agency. Freedom becomes an essential element of the enactment of agency. The issue of freedom is hardly elevated in any discussion of teacher agency, and if it is raised as a focus of inquiries, it is given a scant attention. On the face of it, freedom in exercising agency ought to be viewed as a practice of freedom. This can be done through explicating Foucault's idea of technologies of the self, or as Nilson (1998) calls it "the technologies of the self as practices of freedom" (p. 97). The Foucaldian notion of freedom here is interpreted by Nilson (1998) not as freedom in a very general term such as that of freedom of speech guaranteed by state or law, but as "technologies of mastery, which are based on the individual's relation to himself and others" (p. 98). To this, Martin (1988) said that "true freedom was the moral freedom of a philosophical self-knowledge which recognized and conformed to an assumed orderly principle of the cosmos" (p. 51). Construed in the latter sense, "freedom is practised, and not how one frees oneself (p. 98) [italic in original]. Borrowing Foucault, Nilson (1998) relates practices to self-technologies governmentality.

Technologies of the self is one among the four types of technologies elucidated by Foucault (1988). This specific type of technologies aims to "permit individuals to effect by their own means or with the help of others a certain number of operations on their own bodies and souls, thoughts, conduct, and way of being, so as to transform themselves in order to attain a certain state of happiness, purity, wisdom, perfection, or immortality" (Foucault, 1988 p. 18). It is clear here that agency as a capacity of individuals requires freedom as a requisite to enact agency.

Critical, sociological, and ecological perspectives of agency used as philosophical orientations to the studies reviewed above have fallen short of fathoming the essential condition of freedom in the agency enactment. Take a specific perspective of critical pedagogies. With the backdrop of this perspective, the so-called "collective agency" has been argued to have a transformative capacity in a situation where the unequal power relation persists. The problematics that remain here are how one can exercise and unleash freedom to enact one's individual agency, and then to establish connections with societies so as to pursue collective agency. To make things more complicated, how can in the end an equal power relation in an institutional context like schools be attained unless it remains unclear how one practices freedom to enact one's agency? These are some major problematics that these critical and other perspectives have failed to address. Obviously without knowledge of oneself as the fundamental principal in this modern world (Foucault, 1988), the problems will remain intact and be insurmountable. 
One plausible way to find the solution to the quandaries is that we treat agency as individuals' capacity or property inherent in our self -as part that constitutes technologies of the self. In doing so, we will eventually be cognizant that agency is inescapable from oneself, that it is governed by oneself, and that whose enactment depends on the freedom we unleash through self- technologies governmentality. It is in fact the individual persons who can govern their own bodies, souls and thoughts to enact their agentive capacity.

It is important to reiterate here that placing a trust in agency as an inherent property of individual is not meant to repudiate the import of establishing a social rapport to attain a collective agency, as well as to deny its ecological embeddedness. Rather, it is intended to set up the priority of knowing oneself - the excavation and exploration of technologies of the self.

\section{Agency as Actionality}

To manifest agency in concrete situations (i.e. to realize its social and ecological alignment), it is incumbent upon as to understand its unstable and transitional nature. This is to say that agency is what we perform as part of our technologies of the self. Agency then is a conduct or actionality within individuals. This perspective of agency allows us to broaden our perception that agency is a dynamic notion, and is always in motion and in transition within oneself. As Koopman (2014) puts it: "Conduct is, in every instance, in motion. Conduct is pre-eminently a doing rather than a thing done" (p. 167). On the contrary, seeing its dynamic in relation to the engagement of social relations misses much of its dynamic within individual teachers, and tends to resort to a thing done. It is rather surprising that though Biesta et al. (2020) do acknowledge and attribute their ecological approach to studying agency to the pragmatist philosophy, they seem to have diverted the doing to overcoming the problems arising in a certain situation. As such, agency is defined as "an emergent phenomenon of actor-situation transaction" (Biesta et al., 2020, p. 626). While this extension is plausible, an overemphasis on this will result in the undermining of the dynamic of agency within individuals.

It is thus incumbent upon us to a have closer look at how agency is manifested through conduct or action. The details of the idea of actionality are well expressed by Koopman and Garside (2019) below:

According to this actionistic perspective, it's all motion. That which seem such changeable is always somehow already becoming something other than it just was. Nothing is unmoving though there is much that appears this way because it moves at an exceedingly slow rate of change. But nothing is forever sat still (p. 741).

Construing agency in this actionistic sense implies the continuous construction and reconstruction of one's self, to begin with, before one can make an engagement with others. As part of technologies of the self, agency needs to be manifested through conduct so as to have the effects both on the individuals themselves, as well as on others. The dynamic of teacher agency ought to be realized through conduct or action in real circumstances. Thus, agency as actionality does not repudiate the import of the embeddedness of action in relation to the social relation. In fact, as Koopan and Garside (2019) have argued, the idea of "actionistics are not necessarily restrained to 
being individual humans" (p. 742). It urges instead the establishment of priority over the doing from oneself then to the others.

Most importantly, viewing agency as actionality might also open up "the ontology of agency and multiplies possible answers to the ever-present question of 'who' the subject of action is" (Koopman \& Garside, 2019, p. 743). Actionistic perspective of agency then allows us to see, reflect, and explore our agentive capacity in a contextual and meaningful fashion, prior to its alignment to the social realities. To the extent that social and material worlds accordingly affect the enactment of agency does not render the idea of agency devoid of its ontological basis residing in individuals. Neither does this imply a state of immobility of agency. Quite the opposite, social, critical, and ecological perspectives of agency further strengthen the notion of agency both as technologies of the self and as conduct and action.

\section{Enacting the Re-conceptualized Agency through the Art of Articulation: Implications for ELT Micro-Centric Policy Making}

With the reconceptualization of agency both as technologies of the self and as actionality, how can an individual teacher, and probably a group of teachers especially those who teach English in a specific local site, enact their individual and collective agency? Further, in a certain educational practice where policies are often one-sidedly imposed on them, how do English language teachers (individually and collectively) interrogate them?, how can they articulate their voices in negotiating the ELT policies, so as to create their own micro-centric policy that fits to their local cultural and linguistic needs and purposes ?, and how can they deal with the possible physical, ideological and cultural challenges which may not necessarily accord with their own interests.

Based on the alternative understandings of agency as technologies of the self and agency as actionality elucidated above, I propose here the idea which captures these understandings well-the art of articulation initially conceptualized by Gallagher (2012) as an act of one's self-expression and the juxtaposition of two entities relationally. For Gallagher, the art of articulation is not an end in itself, but a means to achieve the end. It is not aimed at achieving permanent and predictable educational outcomes, but rather an on-going dynamic practice. In essence, "articulation is always a matter of struggle in a war of positions where nothing is certain ahead of time but rather a matter of practice. No outcome can be guaranteed [. . .] by the laws of history but must be determined concretely at specific conjunctures of history" (Trimbur, 2011, as cited in Gallagher, 2012, p. 58). Clearly, the conceptualization implies the technologies of the self as practices of freedom, that is, self-technologies governmentality, as well as an ongoing conduct and action.

As the idea of micro-centric policy making in ELT has now been gaining tractions among scholars (see Sugiharto, 2021), one's art of articulation is highly germane, for it can pave the way for the teachers to contest any ideological stances (infused in the policy) that are felt incompatible with their specific sites and localities. In fact, one essential facet in the micro planning is the recognition of teacher agency and transformation (Sugiharto, 2021). In this policy perspective, agency resides in individual teachers as policy makers, thus enabling them to exercise their latitude to determine what and how to teach, to develop a plan for action, and consequently who "hold agency and 
create what can be recognized as a language policy and plan to utilize and develop their language resources; one that is not directly the result of some larger macro policy, but is a response to their own needs, their own 'language problems', their own requirement for language management" (Baldauf, 2006, p. 155).

To implement this micro planning, it is imperative to fathom the conception of ELT not as an innocent practice. Instead, we need to view ELT practices as a politically- and ideologically contested site. Both political and ideological awareness are vital in the creation of micro language planning (Manan, Channa, Khemlani David, and Amin 2021). That is, ELT practices are a site where the created policies are not neutral-free, but are always produced and reproduced subjectively by collective parties involved in the policy making. On the face of this, teachers need to develop a critical consciousness to interrogate the policy by (re)activating their agentive capacity to successfully implement the micro-centric policy. Consider, for example, the case of the implementation of the English language teaching policy in a local site like multilingual and multiethnic Indonesia (Sugiharto, 2020) where almost all privately-run schools are the fertile ground for the reproduction of an English monolingual ideology. These schools have been strictly imposing the state-mandated English-Only-Policy. In such a situation the class instruction is conducted exclusively in English, and the use of translanguaging by mixing English with the students' native languages is strongly prohibited. Yet, as the teachers found this policy not always viable, given the students' varied English proficiency levels, they often interrogated this policy surreptitiously by resorting to the Indonesian language when interacting with the students in the classroom. Such is the case where teachers attempt to treat a classroom as a dynamic communicative space where they enact their agency, so as to meet their students' communicative needs. Despite the fact that this agency enactment was done on the sly, the teachers are able to (re) activate and perform their agentive capacity, creating a spontaneous micro-centric policy that covertly, but strategically resists the English monolingual ideology.

Another compelling instance elucidating the enactment of the power of individual agency in a local site is a study by Manan et al., (2021). Manan et al. (2021) have shown the prevalence of English monolingualism ideology in elite schools in Pakistan where teachers are strictly proscribed to use students' native languages in a classroom interaction. Teachers will risk losing their career if they interact using mixed linguistic codes. Manan et al., (2021) have found that despite the strict implementation of the English-centric policy, the Pakistani teachers managed to create "agentive spaces of a multilingual environment" where they explored their agentive capacity and critically interrogate and resist the policy. In so doing, the teachers have demonstrated their strong convictions about their own genuine teaching experiences, as well as the complexities of English language teaching practices in a local context which cannot be prescribed and pre-determined by the English-centric policy.

From the instances above we can infer that we cannot rule out the possibility that there exists "authoritarian tendencies, whose educational manifestation is an epiphenomenon of broader social and political machinations" (Koopman \& Garside, 2019, p. 744). The English-centric policy is just one instance. We can therefore plausibly surmise that educational products may contain subjectivities and biases which might not necessarily be congenial to classroom teachers who put 
them in practice. In this respect, the products can always be contested, and are therefore subject to negotiation and resistance.

The art of articulation plays a vital role here, in that it provides a space for the enactment of agency. It affords teachers the opportunity to negotiate tensions that may exist when they juxtapose the imposed language policy vis-à-vis their very agency articulated in the form of the de facto language policy. It is very encouraging to witness a shift of orientation in language planning and policy scholarship which no longer views policy as" totalizing entities that happen to people or that create hierarchies" to seeing policy as "realms where we start thinking more about what we can do with policies in the contingencies of our work" (Ramanathan \& Morgan, 2007, pp. 450-451). Under the latter vantage point, language teachers are no longer seen as "passive recipients of fixed, immutable codes", but instead as "active sign-makers (p. 451). They are now de facto language planners and policy makers of the specific site where they conduct their teaching practices relative to their positionality.

The creation of de facto language policy as a micro-centric policy implies continuous endeavors of making a space of possibility, or in the ELT context, spaces of multilingual environment, as well as of struggling for articulating our voices to be heard and enacted. This can only be viable if we optimally exercise our self-technologies governmentality and conduct as a real manifestation of agency enactment both individually and collectively. Both governmentality and conduct in agency enactment need to eventually form a sediment, which is to say that they manifest as authority within individuals. The authority in practicing education is important, given the incessant cultural and ideological imposition from those who subscribe to the "epistemologically authoritarian visions of schooling" (Koopman \& Garside, 2019, p. 744).

\section{References}

Baldauf, R. B. Jr. (2006). Rearticulating the case for micro language planning in a language ecology context. Current Issues in Language Planning, 7, 147-170. https://doi.org/10.2167/cilp092.0

Bandura, A. (2006). Toward a psychology of human agency. Perspectives on Psychological Science, 1(2), 164-180. https://doi.org/10.1111/j.1745-6916.2006.00011.x.

Biesta, G., Priestley, M., \& Robinson, S. (2015). The role of beliefs in teacher agency. Teachers and Teaching: Theory and Practice, 21(6), 624-640, http://dx.doi.org/10.1080/13540602.2015.1044325.

Bridwell-Mitchell, E.N. (2015). Theorizing teacher agency and reform: How institutionalized instructional practices change and persist. Sociology of Education, 88(2), 140-159. https://doi.org/10.1177/0038040715575559.

Foucault, M. (1988). Technologies of the self. In. L. H. Martin, H. Gutman, \& P. H. Hutton (Eds.), A Seminar with Michel Foucault (pp. 16-49). Amherst, Mass.: University of Massachusetts Press.

Gallagher, C. (2012). The trouble with outcomes: Pragmatic inquiry and educational aims. College English, 75(1), 42-60.

Heikkilä, M., T. Iiskala, and M.M. Mikkilä-Erdmann. (2020). Review article: Voices of students teachers' professional agency at the intersection of theory and practice. Learning, Culture and Social Interaction, 25, 1-11. https://doi.org/10.1016/j.lcsi.2020.100405.

Imants, J. and der Wal, M.M. (2020). A model of teacher agency in professional development 
and school reform. Journal of Curriculum Studies, 52(1), 1-14.

https://doi.org/10.1080/00220272.2019.1604809.

Manan, S., Channa, L.A., Khemlani David, M., and Amin, M. (2021). Negotiating English-only gatekeepers: Teacher's agency through a public sphere lens, Current Issues in Language Planning, 22(3), 290-307. https://doi.org/10.1080/14664208.2020.1839219.

Koopman, C. (2014). Conduct pragmatism: Pressing beyond experientialism and lingualism, European Journal of Pragmatism and American Philosophy, 6(2), 145- 174. https://doi.org/10.4000/ejpap.313.

Koopman, C and D. Garside. (2019). Transition, action and education: Redirecting pragmatist philosophy of education, The Journal of Philosophy of Education, 53(4), 734-747. https://doi.org/10.1111/1467-9752.12399.

Nilson, H. (1998). Michel Foucault and the games of truth (trans.Rachel Clark). New York: ST Martin's Press.

Ramanathan, V. and Morgan, B. (2007). TESOL and policy enactments: Perspectives from practice. TESOL Quarterly, 41, 447-463. https://doi.org/10.1002/j.15457249.2007.tb00080.x.

Rostami, F. and Yousefi, M.H. (2020). Iranian novice English teachers' agency construction: The complexity/dynamic system perspective. Asia-Pacific Journal of Second and Foreign Language Education, 5(4), 1-16. https://doi.org/10.1186/s40862-020-00082-2.

Samoukovic, B. (2015). Re-conceptualizing Teacher Expertise: Teacher Agency and Expertise through a Critical Pedagogic Framework. Unpublished Dissertation. University of Iowa.

Sugiharto, S. (2020). From policies as entities to policies as engagements: Transforming English language teachers into ELF-aware practitioners, International Journal of Applied Linguistics, 30(3), 413-428. https://doi.org/10.1111/ijal.12293 